\title{
GLICOSE PARA O ALÍVIO DA DOR EM RECÉM-NASCIDOS E SUA APLICAÇÃO EM TRANSPORTES AEROMÉDICOS
}

Michelle TAVERNA ${ }^{1}$, Liandra Kasparowiz GRANDO ${ }^{2}$, Vanessa COLDEBELA ${ }^{3}$ e Rafaela dos Santos Portugal NOGUEIRA ${ }^{4}$

\section{RESUMO}

O transporte aeromédico de pacientes recém-nascidos é bastante recorrente em nosso país, normalmente acometidos de patologias que necessitam de internações desde o nascimento com um número expressivo de intervenções invasivas e dolorosas, por isso já é comum, entre profissionais que trabalham em UTIs neonatais, a busca por terapias complementares e/ou não farmacológicas como alternativas para redução de estressores ambientais, alívio da dor e aumento do bem-estar. Esse trabalho se trata de uma pesquisa bibliográfica do tipo exploratória nas bases de dados online MEDILINE, LILACS e SciELO, no período de 2010 a 2021 . Sabendo que a glicose oral/sublingual tem boa repercussão e evidências substanciais no manejo da dor em procedimentos realizados nas UTIs como por exemplo: acessos venosos, passagem de sondas, trocas de fixações de tubos e drenos, partiremos para próxima fase da pesquisa que será busca por resultados na sua aplicação como alternativa na redução de estressores de voo.

Palavras-chave: métodos não farmacológicos, dor em recém-nascidos.

\section{INTRODUÇÃO}

Trabalhar com transporte de neonatais é um privilégio para muitos profissionais de saúde e quando se fala de pacientes críticos inevitavelmente falamos em alta performance profissional aliada a tecnologia de ponta, tais recursos são essenciais para otimizar a sobrevida e minimizar sequelas.

Em Unidade de Terapia Intensiva Neonatal (UTIN) pela necessidade de realização de procedimentos invasivos de rotina, a dor é uma presença constante durante a inter-

\footnotetext{
1. Enfermeira de Voo Helisul, $1^{\circ}$ Ten da Força Aérea, Presidente ABRAERO, Coordenadora do Dep. de Neurociência da ABRAERO. Curitiba, Paraná, Brasil. michelletaverna@hotmail.com

2. Enfermeira de voo. Especialista em Medicina Aeroespacial e Transporte Aeromédico. Membro e Coordenadora Adjunto do Dep. de Neonatologia da ABRAERO, Curitiba, Paraná, Brasil. liandrakg@gmail.com

3. Enfermeira de voo. Especialista em Medicina Aeroespacial e Transporte Aeromédico. Membro e Coordenadora do Dep. de Neonatologia da ABRAERO, Curitiba, Paraná, Brasil. vanessacolde@gmail.com

4. Médica de voo Helisul. Curitiba, Paraná, Brasil. rdsportugal@gmail.com
} 
nação de recém-nascido prematuro (RNPT) (MARTINS et al, 2013).

O transporte aeromédico de pacientes recém-nascidos é bastante recorrente em nosso país, normalmente acometidos de patologias que necessitam de internações desde o nascimento com um número expressivo de intervenções invasivas e dolorosas. Por isso, já é comum entre profissionais que trabalham em UTIs neonatais a busca por terapias complementares e/ou não farmacológicas como alternativas para redução de estressores ambientais, redução da dor e aumento do bem-estar (MARTINS et al, 2013).

\section{METODOLOGIA}

Realizou-se uma pesquisa bibliográfica do tipo exploratória nas bases de dados online MEDILINE, LILACS e SciELO, integrantes do sistema BIREME, no período de 2010 a 2021. Sendo considerado principalmente artigos, capítulos de livro e teses. Os descritores utilizados foram: recém-nascidos, dor e glicose. Posterior prosseguimos com leitura analítica para determinar quais materiais se enquadravam na finalidade da pesquisa.

\section{RESULTADOS E DISCUSSÕES}

Bebês cada vez menores estão conseguindo sobreviver a prematuridade devido a evolução da medicina e a inclusão da tecnologia de ponta nas UTI's neonatais. Entretanto essa maior performance tecnológica trouxe consigo alguns "malefícios" pois transformou esses ambientes em locais barulhentos e estressantes para os recémnascidos podendo desencadear dor e irritação. Isso também se estende às UTIs aéreas. Com uso de aviões e helicópteros são adicionados alguns componentes a mais: ruído dos motores, vibrações, variações de temperatura, aceleração, hipóxia e variação da pressão.

Segundo estudos, em média, um recém-nascido recebe cerca de 130 a 234 manipulações nas primeiras 24 horas de vida. Sendo que durante sua internação, por dia, em média são aplicados 16 procedimentos potencialmente dolorosos (MARTINS et al, 2013). Os autores acrescentam que os procedimentos que produzem mais dor em UTINs, são: punções venosas, sondagens orogástricas e vesicais, glicemia capilar, 


\section{CON

curativos, aspiração de vias áreas e intubação orotraqueal. Além disso, existem ruídos, luzes fortes contínuas e manuseio constante. (FREITAS; PEREIRA; OLIVERIA 2012 e CRUZ, et al, 2016).

A maioria dos hospitais tem trabalhado a aplicação protocolos, escalas e rotinas específicas para a prevenção e tratamento da dor em pacientes críticos. Dentro da escada do tratamento de dor, a base está na prevenção, passando para a analgesia não farmacológica, indo para a analgesia tópica, passando por antinflamatórios não hormonais, opioides, depois anestesias locais e profundas (GUINSBURG, 2019).

Em recém-nascidos a dor pode ser avaliada, principalmente pelos indicadores comportamentais, como choro, mímica facial e atividade motora em procedimentos de rotina, moderados a extremamente dolorosos e fisiologicamente podem apresentar taquipnéia, taquicardia, diminuição na saturação de oxigênio, aumento da pressão arterial, da pressão intracraniana e sudorese palmar (MARTINS et al, 2013).

Desencadeando uma resposta ao estresse que inclui modificação em nível cardiovascular, respiratório, imunológico, hormonal e comportamental, entre outros. Essas respostas fisiológicas são acompanhadas por uma reação endócrino-metabólica de estresse, com liberação de hormônios como adrenalina, noradrenalina e cortisol, podendo resultar em hiperglicemia e catabolismo proteico lipídico, o que interferindo no equilíbrio homeostático (CRUZ, et al., 2016).

STEVENS (2016) em sua revisão contabilizou 74 estudos que incluíram no total de mais de 7.000 bebês. Concluiu que existe evidência de alta qualidade de que a sacarose reduz diferentes medidas de dor de bebês recém-nascidos durante a punção do calcanhar, punção venosa e injeção intramuscular. Porém, sem melhora efetiva da dor durante a circuncisão.

Considerando as controvérsias dos grupos que utilizam analgesia alguns utilizam opioides de rapidíssima ação. Em entrevista GUINSBURG (2019) disse que não existe ainda uma droga de ótima atuação e reconhece as evidências na aplicação da glicose como alternativa para o alívio da dor em recém-nascidos em outros procedimentos, podendo este ser utilizado como estratégia não farmacológica e com melhores resultados, se possível, em sinergismo com a sucção não nutritiva. (GUINSBURG, 2019) Os estudos consideram o uso de 2 gotas de glicose/sucarose por via oral/sublingual 2 minutos antes da execução de procedimentos. Avaliaremos a possiblidade desta terapêutica 2 minutos antes da transferência para incubadora da aeronave. 


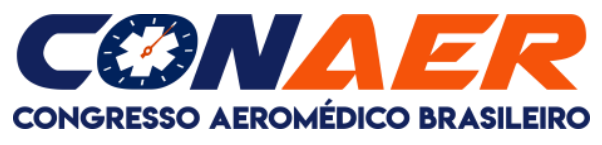

Oferecer ferramentas para a equipe de voo no manejo não farmacológico da dor durante a realização de procedimentos estressantes/ dolorosos em recém-nascidos, pode ser um grande aliado para diminui-los e quem sabe também com repercussão na redução dos efeitos fisiológicos ocasionados pelos estressores de voo durante as transferências aéreas.

\section{CONSIDERAÇÕES FINAIS}

Por dia, em média são aplicados 16 procedimentos potencialmente dolorosos nos recém-nascidos prematuros (RNPT) (MARTINS et al, 2013). No intuito de reduzir os danos causados por esses procedimentos dolorosos e a permanência em ambiente desgastante como as UTI, repletas de alarmes, luzes e demais ruídos, muitos profissionais buscam uma forma de humanizar através de várias terapias integrativas e/ou não farmacológicas. Os principais exemplos são: amamentação, musicoterapia, contato pela a pele, hora do soninho, terapia do riso (com palhaços), uso de sacarose/glicose entre outros.

É unanime entre os autores pesquisados que há evidências substanciais para o uso da glicose sublingual como alternativa para minimização de dor em procedimentos. Quando colocamos um paciente em um avião ou helicóptero devemos considerar os estressores a que estes bebês são submetidos tais como: alteração de leito, ruídos, vibrações, variações de temperatura, excesso de luminosidade, acelerações entre outros. E é observando a aplicação da glicose sublingual com seu efeito benéfico no alívio da dor em recém-nascidos durante suas internações em UTIs que partiremos para próxima fase da pesquisa que será a introdução desta técnica na intenção da redução da sensibilidade aos estressores de voo durante os transportes aeromédico. Levando em consideração que a equipe de voo avalie a dor do RN embasada em evidências científicas, aliadas à criação de políticas institucionais sobre controle da dor durante o transporte aeromédico, com uso de instrumentos de mensuração validados, bem como protocolos de analgesia e atividades de educação permanente em serviço. 


\section{CONAER \\ CONGRESSO AEROMÉDICO BRASILEIRO}

\section{REFERÊNCIAS}

CRUZ, C.T., et al. Avaliação da dor de recém-nascidos durante procedimentos invasivos em terapia intensiva. Rev. dor 17. Publicada em: 2016. Disponível em: https://doi.org/10.5935/1806-0013.20160070. Acessado: 14 de junho de 2021.

GUINSBURG,R.. Principais Questões sobre Estratégias não farmacológicas para Controle da Dor em Recém-nascidos. Publicado no Portal de Boas Práticas em Saúde da Mulher, da Criança e do Adolescente em 2019. Disponível em: https://portaldeboaspraticas.iff.fiocruz.br/atencao-recem-nascido/principais-questoessobre-estrategias-nao-farmacologicas-para-controle-da-dor-em-recem-nascidos/.

Acessado: 16 de junho de 2021.

FREITAS ZM, PEREIRA CU, OLIVEIRA DM. Escalas para avaliação de dor em neonatologia e sua relevância para a prática de enfermagem. Pediatria Moderna. Publicada em Setembro de 2016. Disponível em: https://doi.org/10.5935/18060013.20160070. Acessado: 14 de junho de 2021.

MARTINS, S.W. et al. Avaliação e controle da dor por enfermeiras de uma unidade de terapia intensiva neonatal. Rev. dor 14. Publicada em Março de 2013. Disponível em: https://doi.org/10.1590/S1806-00132013000100006. Acessado: 14 de junho de 2021.

STEVENS B, et al. Sacarose para analgesia (alívio da dor) de recém-nascidos submetidos a procedimentos dolorosos. Sacarose para analgesia (alívio da dor) de recém-nascidos submetidos a procedimentos dolorosos. Publicado em julho de 2016 em Cochrane. Disponível em: https://www.cochrane.org/pt/CD001069/NEONATAL_sacarose-paraanalgesia-alivio-da-dor-de-recem-nascidos-submetidos-procedimentos-dolorosos.

Acessado: 14 de junho de 2021. 